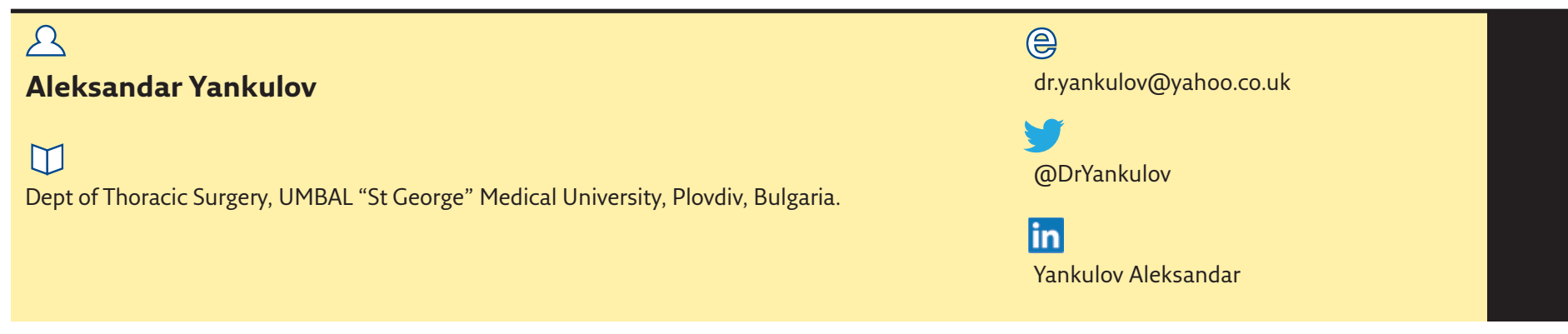

\title{
ERS clinical fellowship report
}

My name is Aleksandar Yankulov and I am a thoracic surgeon from UMBAL "St George" Medical University, Plovdiv, Bulgaria. I have had the unique opportunity to be part of one of the first European Respiratory Society (ERS) clinical fellowships. When I first saw the announcement for this fellowship, I had a clear idea of what I could use it for. Our country is one of the few where patients in the terminal stages of lung disease cannot be treated adequately due to the lack of a lung-transplant programme. As a young surgeon I have read a lot of papers concerning this procedure and it was my intention to spend time as a visiting fellow at the Medizinische Hochschule, Hannover and their transplant unit (the highest volume transplant center in Europe and the second highest in the world). The ERS fellowship was an ideal tool to allow me to visit this department for a longer period and, as I do not have experience with this procedure, I decided to stay the maximum period ( 6 months). My application was accepted by the head of the transplant unit, G. Warnecke, and, after a positive answer from the ERS authorities, I began my visit on February 1, 2016. I never realized how well organised the lung-transplant programme in Hannover is. By their hospitality and their willingness to show me as much as possible in the field of lung transplantation, I had the opportunity to see all aspects of surgical procedure, starting from the standard, most-often used double lung transplantation through to single lung procedures, heart-lung transplantation, lobar transplantation and paediatric cases. As I was also included in the harvesting process I visited almost all of Germany's cities and most Eurotransplant countries. Due to this huge travel experience I had a chance to see the transport of donor lungs with organ care system (OCS) devices. During my stay I developed my understanding of the main principles of early and late postoperative care of transplanted patients, including postoperative use of extracorporeal membrane oxygenation (ECMO), signs of acute rejection, how to treat infections and their complications in transplanted patients, and how to organise a database for transplanted patients. I was involved in ambulatory meetings with candidates for listing for transplantation and also transplanted subjects. For these 6 months I had a chance to watch and assist on around 50 cases which was unique and very useful experience for me as a thoracic surgeon. The knowledge of, and good relationships with, my Hannover colleagues will help me in my efforts to organise such a programme in my country. This is going to have not only financial benefit for Bulgaria but is also going to be a huge relief for our listed patients, who must travel, stay and be operated upon in a foreign country without the psycho-emotional support of their relatives, one of the most important parts of a successful lung-transplant programme!

\section{Acknowledgements}

I want to say a big thank you to the ERS for the excellent opportunity to stay so long in such an experienced center in the field of lung transplantation as the Klinik für Herz-, Thorax-, Transplantationsund Gefäßchirurgie (HTTG). I am grateful to all my mentors in the field of lung transplantation: A. Haverich, G. Warnecke, I. Tudorache, C. Kuhn,
Cite as: Yankulov A. ERS clinical fellowship report. Breathe 2017; 13: 5-6. 
M. Avsar, N. Koigeldiyev, T. Kaufeld, W. Sommer, F. Lus, M. Roumieh, J. Salman, T. Simeni, D. Bobylev, S. Rojas, A. Molgadea, S. Rumke, T. Goecke, and R. Poyanmehr (for the steady nerves in allowing me to follow him and ask questions every morning during visitation). I am also grateful to R. Machunze and I. Kuhne (for the best cookies during ambulatory meetings) and to all the staff of the department (other colleagues, ward and operative nurses) for their hospitality. I hope we are able to collaborate with each other in the near future!

\section{Conflict of interest}

None declared. 